\title{
The Beneficial Effect of Hydrogenase in Azotobacter chroococcum Under Nitrogen-fixing, Carbon-limiting Conditions in Continuous and Batch Cultures
}

\author{
By O. M. AGUILAR, $†$ M. G. YATES* And J. R. POSTGATE \\ AFRC Unit of Nitrogen Fixation, University of Sussex, Brighton BNI 9RQ, UK
}

(Received 14 March 1985; revised 19 June 1985)

\begin{abstract}
The growth of three hydrogenase minus ( $\mathrm{Hup}^{-}$) mutants of Azotobacter chroococcum was compared with that of the parent $\mathrm{Hup}^{+}$strain in batch or continuous cultures. All three mutants gave similar yields to the parent under $\mathrm{N}_{2}$-fixing conditions at an optimum dilution rate $(D)$ of $0 \cdot 1 \mathrm{~h}^{-1}$ in sucrose-limited $\mathrm{N}_{2}$-fixing cultures. However, at higher $D$ values the steady-state yields of sucroselimited mutants were lower than those of the parent and washout occurred at lower $D$ values. These observations were confirmed in carbon-limited mixed cultures where the parent strain outgrew the mutant at high $D$ values. Such marked differences were not obtained in $\mathrm{SO}_{4}^{2-}-$ or $\mathrm{O}_{2}$-limited continuous cultures. In batch culture at low sucrose levels the mutants displayed a long division lag compared with the parent, particularly with dilute inocula. Non- $\mathrm{N}_{2}$-fixing $\left(\mathrm{NH}_{4}^{+}\right.$-grown) conditions removed these differences. We suggest that one beneficial effect of hydrogenase is on the initiation of diazotrophic growth, particularly with restricted carbon/energy supply.
\end{abstract}

\section{INTRODUCTION}

Although hydrogen is a normal by-product of nitrogenase function (see Postgate, 1982), aerobic diazotrophs rarely evolve $\mathrm{H}_{2}$ when fixing $\mathrm{N}_{2}$. Exceptions are some strains of Rhizobium and Bradyrhizobium (see Evans et al., 1981) and Azotobacter chroococcum grown under certain physiological conditions (Yates et al., 1981) or pre-treated with an inactivator of hydrogenase, acetylene (Walker et al., 1981). $\mathrm{H}_{2}$ evolution by nitrogenase represents a metabolic drain on the organisms since ATP is consumed and, presumably, wasted. $\mathrm{H}_{2}$ production can use 25 to $80 \%$ of the electron flux to nitrogenase in vivo (Evans et al., 1981; Yates et al., 1981). Most diazotrophs possess a hydrogenase; in aerobes such as the azotobacters and rhizobia the enzyme is essentially unidirectional, catalysing the uptake of $\mathrm{H}_{2}$. It is believed to contribute to the metabolic efficiency of the diazotrophic system by scavenging $\mathrm{H}_{2}$ produced during the nitrogenase function; possible benefits (Dixon, 1972) include sparing of electron sources for diazotrophy, recovery of ATP through $\mathrm{H}_{2}$-linked respiration, respiratory protection of nitrogenase against $\mathrm{O}_{2}$ and protection of the enzyme from inhibition by $\mathrm{H}_{2}$ (see Robson \& Postgate, 1980).

Hydrogenase ought therefore to increase the metabolic efficiency of aerobic diazotrophy. This matter has been much studied in the legume symbiosis, in plants inoculated with either $\mathrm{Hup}^{+}$or Hup ${ }^{-}$strains of rhizobia with conflicting results. Evans et al. (1985) estimated that only $61 \%$ of all experiments had shown a positive response (higher yields and nitrogen contents) to inoculation with Hup ${ }^{+}$over $\mathrm{Hup}^{-}$strains.

These data are no doubt much influenced by the complexities of the legume symbiosis. A nonsymbiotic diazotroph is, in principle, a physiologically simpler system with which to analyse the metabolic role of hydrogenase in diazotrophy. In the present work we compared the growth of Hup $^{-}$mutants of Azotobacter chroococcum with the Hup ${ }^{+}$parent strain in batch and continuous cultures under different nutrient limitations.

†Present address: Fakultät für Biologie, Universität Bielefeld, Postfach 8640, 4800 Bielefeld 1, FRG. 


\section{METHODS}

Growth of bacteria. Azotobacter chroococcum MCD-1 is a spontaneous streptomycin and nalidixic acid resistant mutant of a non-gummy variant of $A$. chroococcum NCIMB 8003 (Robson et al., 1984). A. chroococcum MCD-105, 119 and 122 are uptake hydrogenase negative (Hup ${ }^{-}$) mutants obtained by mutagenesis with $N$-methyl- $N^{\prime}$-nitro$N$-nitrosoguanidine (MNNG) (Yates \& Robson, 1985). They were grown in batch culture on Burk's N-free medium (Newton et al., 1953) with or without $\mathrm{NH}_{4} \mathrm{Cl}(18 \mathrm{mM}$ ). Continuous cultures were grown in 1-litre glass vessels (Baker, 1968) with a working volume of approximately $450 \mathrm{ml}$ under air at $30^{\circ} \mathrm{C}$. Burk's medium was added by a dual-feed system to avoid the use of chelating agents which inhibit hydrogenase synthesis (Partridge $\&$ Yates, 1982). The $\mathrm{pH}$ was maintained at $7.0 \pm 0.05$ by means of a $\mathrm{pH}$ controller (Uniprobe 706 ) and $\mathrm{O}_{2}$ in solution was monitored by an $\mathrm{O}_{2}$ electrode fitted through a side port. $\mathrm{O}_{2}-$ and carbon- limited cultures contained 58.4 and $4.5 \mathrm{~mm}$-sucrose respectively; for $\mathrm{SO}_{4}^{2-}$-limited cultures, sulphates were replaced by chlorides and $\mathrm{Na}_{2} \mathrm{SO}_{4}$ was added to $50 \mu \mathrm{M}$. Nutrient limitations were confirmed by determining residual $\mathrm{O}_{2}$, sucrose or sulphate concentrations in the culture fluid and by showing that the yields increased only in response to additional limiting nutrient (Dalton \& Postgate, 1969). $\mathrm{NH}_{4}^{+}$-utilizing, non- $\mathrm{N}_{2}$-fixing conditions were confirmed by an inability to reduce acetylene.

Yields were determined as dry weights in triplicate.

Batch cultures. Batch cultures of $A$. chroococcum were grown in $250 \mathrm{ml}$ conical flasks containing Burk's medium $(100 \mathrm{ml})$ on a rotary shaker $\left(60\right.$ r.p.m.) under air at $30^{\circ} \mathrm{C}$. The flasks were fitted with a side tube to allow growth measurements by $\mathrm{OD}$ at $540 \mathrm{~nm}$ using a Klett spectrophotometer.

Mixed populations. The percentage of $\mathrm{Hup}^{+}$bacteria in mixed populations of the parent strain and a Hup ${ }^{-}$ mutant was determined by a modification of the 'scrying' technique (Postgate et al., 1982; Haugland et al., 1983). The mixed culture was serially diluted to $2 \times 10^{4}$ cells ml-1 and plated on Burk's sucrose agar containing $25 \%$ of the normal $\mathrm{Ca}^{2+}$ level. The developed colonies were absorbed on to filter paper (Whatman no. 1), soaked in a solution of $50 \mathrm{~mm}$-sodium phosphate buffer, $\mathrm{pH} 8.0$, methylene blue (1 mM), NaF (150 mM), EDTA (4 mM), iodoacetic acid $(200 \mu \mathrm{M})$ and malonic acid $(200 \mu \mathrm{M})$ for $20 \mathrm{~min}$ and then exposed to $\mathrm{H}_{2}$ for $20 \mathrm{~min}$. White spots represented $\mathrm{Hup}^{+}$colonies.

\section{RESULTS}

\section{Continuous cultures of individual populations}

Yields of all three Hup ${ }^{-}$mutants and the $\mathrm{Hup}^{+}$parent strain in $\mathrm{N}_{2}$-fixing, carbon-limited continuous cultures (Fig. 1) increased upon increasing the dilution rate from 0.05 to $0.1 \mathrm{~h}^{-1}$, consistent with the report of Dalton \& Postgate (1969). The yield of the parent Hup ${ }^{+}$strain remained constant $(0.3 \mathrm{mg}$ dry wt ml-1 $)$ from $D=0.1$ to $0.2 \mathrm{~h}^{-1}$ and then declined slightly to $0.25 \mathrm{mg}$ dry wt $\mathrm{ml}^{-1}$ at $D=0.27 \mathrm{~h}^{-1}$. At higher dilution rates washing out occurred. The three Hup $^{-}$mutants gave similar optimum yields to the wild-type at $D=0 \cdot 1 \mathrm{~h}^{-1}$. The steady-state yields decreased sharply at $D$ values above a narrow optimum range which differed among the three mutants and were considerably lower than those of the parent strain at dilution rates above $0 \cdot 1 \mathrm{~h}^{-1}$. A progressive change from high to low dilution rates increased the steady-state yields to a similar maximum at the same optimum $D$ value (data not shown). Yields under carbon limitation in the presence of $\mathrm{NH}_{4}^{+}$showed no clear differences between parent and mutant strains: yields increased slightly from low $D$ values to an optimum and then declined with increasing dilution rate to $D$ values of $0.35 \mathrm{~h}^{-1}$ and the cells washed out.

Yields of $\mathrm{O}_{2}$-limited, $\mathrm{N}_{2}$-fixing cultures of the $\mathrm{Hup}^{+}$parent and MCD-122 declined similarly between $D$ values of 0.05 and $0.2 \mathrm{~h}^{-1}$ (data not shown). Yields of $\mathrm{SO}_{4}^{2-}$-limited cultures of the wild-type and all three mutants were similarly affected across a range of $D$ values from 0.1 to $0 \cdot 2 \mathrm{~h}^{-1}$ although small differences were observed at lower and higher dilution rates (data not shown). This pattern of yields corresponds to the theoretical for the two classes of nutrient limitation.

\section{Batch cultures}

Flask cultures of the three Hup ${ }^{-}$mutants, when inoculated from exponential phase cultures and shaken under air from the time of inoculation, showed longer division lags than the parent $\mathrm{Hup}^{+}$strain, a phenomenon particularly pronounced at higher dilutions in medium containing $10 \mathrm{~mm}$-sucrose (Table 1). Once growth had started, doubling times of all four strains were similar. Similar results were obtained with 20 or $30 \mathrm{~mm}$-sucrose. However, with $58.4 \mathrm{~mm}$-sucrose 


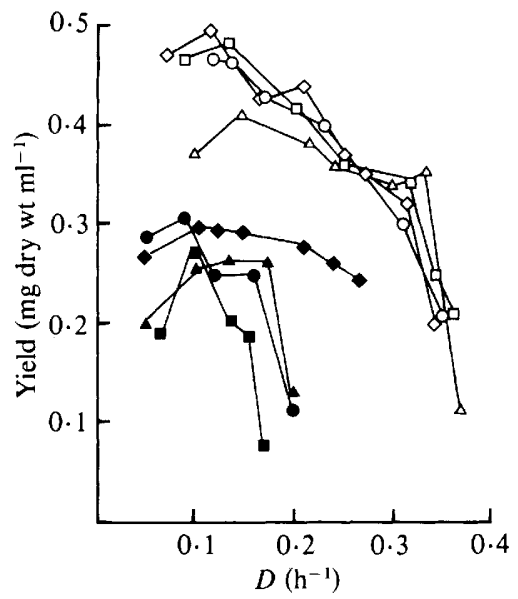

Fig. 1. Effect of nutrient limitations on the steady-state yields of parent (Hup ${ }^{+}$) and Hup ${ }^{-}$strains of $^{-1}$ $A$. chroococcum in carbon-limited continuous culture. Filled symbols, $\mathrm{N}_{2}$-fixing; open symbols, $\mathrm{NH}_{4}^{+}$grown. $\bullet, \diamond, \mathrm{MCD}-1\left(\mathrm{Hup}^{+}\right) ; \boldsymbol{O}, \mathrm{O}, \mathrm{MCD}-105 ; \mathbf{\Delta}, \triangle, \mathrm{MCD}-119 ; \mathbf{\square}, \square, \mathrm{MCD}-122$. The results are the mean of dry weights in triplicate at each steady-state

Table 1. Effect of serial dilution on the growth of $\mathrm{A}$. chroococcum $\mathrm{Hup}^{+}$and Hup strains in $\mathrm{N}_{2}$-fixing culture

Inocula were made from $\mathrm{N}_{2}$-fixing batch cultures shaken under air in exponential phase containing $5 \times$ $10^{8}$ cells $\mathrm{ml}^{-1}$. Each culture was diluted $10^{2}-, 10^{3}$ - and $10^{4}$-fold and $1 \mathrm{ml}$ was inoculated into $\mathrm{N}$-free Burk's medium $(100 \mathrm{ml})$ containing $10 \mathrm{~mm}$-sucrose in a $250 \mathrm{ml}$ conical flask with a side tube for measuring growth as described in Methods. Growth initiation time (zero time for MCD-1 and $10^{-2}$ inoculum) was determined by extrapolated growth curves. The data are from a single experiment. The figures in parentheses are the specific growth rates $(\mu)$ for each culture.

\begin{tabular}{|c|c|c|c|c|c|}
\hline \multirow[b]{2}{*}{ Strain } & \multirow[b]{2}{*}{ Hup } & \multirow{2}{*}{$\begin{array}{r}\text { Serial } \\
\text { dilution }\end{array}$} & \multicolumn{3}{|c|}{ Relative lag (h) } \\
\hline & & & $10^{-2}$ & $10^{-3}$ & $10^{-4}$ \\
\hline MCD-1 & + & & 0 & $2(0 \cdot 168)$ & 35 \\
\hline MCD-105 & - & & 1 & $3(0 \cdot 170)$ & 42 \\
\hline MCD-119 & - & & 3 & $34(0 \cdot 100)$ & 42 \\
\hline MCD-122 & - & & 2 & $37(0 \cdot 158)$ & $\infty$ \\
\hline
\end{tabular}

(the original concentration of this carbon source in Burk's medium) the differences in division lags were not observed. Differences in division lags at $10 \mathrm{~mm}$-sucrose were not observed with $\mathrm{NH}_{4}^{+}$under air or under diazotrophic conditions with $\mathrm{N}_{2}+5 \%(\mathrm{v} / \mathrm{v}) \mathrm{O}_{2}$.

\section{Continuous cultures of mixed populations}

The yield kinetics observed in continuous carbon-limited diazotrophic cultures predict that the Hup ${ }^{+}$phenotype will outgrow the Hup ${ }^{-}$type at higher dilution rates. Mixed cultures were therefore initiated by mixing approximately $200 \mathrm{ml}$ of Hup ${ }^{+}$and Hup ${ }^{-}$strains taken from carbon-limited continuous cultures growing at steady-states $\left(D=0 \cdot 1 \mathrm{~h}^{-1}\right)$. Volumes were adjusted to account for the small differences in cell density. These large volumes were used to establish steady-states rapidly. Samples plated at the time of mixing showed that cultures had approximately equal numbers of viable cells of each type. The behaviour of the mixed populations is illustrated in Fig. 2. In two instances (MCD-122+MCD-1 and MCD$105+$ MCD-1) the Hup ${ }^{-}$mutant tended to out-compete the Hup ${ }^{+}$strain, but at higher dilution rates the $\mathrm{Hup}^{+}$phenotype took over in all cases. Mixtures of MCD-105 and MCD-1 differed from the others in that, on three occasions, the mutant dominated completely at lower dilution rates and attempts to establish mixtures failed because the wild-type washed out. The fourth 


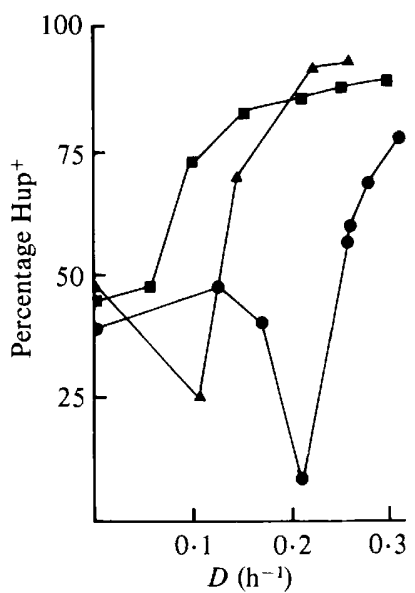

Fig. 2. Take-over by $\mathrm{Hup}^{+}$phenotype at high dilution rates in carbon-limited continuous cultures. Inocula were mixtures from carbon-limited individual populations at $D=0 \cdot 1 \mathrm{~h}^{-1}$. Each steady-state was analysed for the proportions of Hup ${ }^{+}$and Hup' strains by the 'scrying' technique (see Methods) using four replicates at three different serial dilutions $\left(10^{-4}, 10^{-5}, 10^{-6}\right)$. A state was designated steady when the cell density remained constant for five generations, i.e. $(5 \times 1 D)$ h. However we recognize that the proportion of $\mathrm{Hup}^{+}$to Hup ${ }^{-}$mutants may have continued to change during this time, as indicated by the MCD-1:MCD-105 mixture sampled twice at $D=0 \cdot 26 \mathrm{~h}^{-1}$. Points at $D=0$ signify the ratio of phenotypes at the initiation of the chemostat culture., MCD-1:MCD-105;, MCD1: MCD-119; $A$, MCD-1: MCD-122.

attempt is shown in Fig. 2: the proportion of MCD-1 declined to $8 \%$ at $D=0 \cdot 21 \mathrm{~h}^{-1}$ but then increased to $77 \%$ by $D=0 \cdot 31 \mathrm{~h}^{-1}$. MCD-1 remained preponderant $(>90 \%)$ when the mixed cultures with MCD-1 19 or MCD-122 were returned abruptly to a low dilution rate $\left(0.06 \mathrm{~h}^{-1}\right)$ but MCD-105 recovered to such an extent that MCD-1 represented only $0.5 \%$ of the population within 11 generations at $D=0.07 \mathrm{~h}^{-1}$. All three mutants survived at higher $D$ values in mixed cultures with MCD-1 than in pure culture.

Mixed cultures of Hup mutants and the parent type grown in the presence of $\mathrm{NH}_{4}^{+}$did not show consistent dominance patterns; instead, if one partner became dominant the other washed out. Out of six attempts to establish mixed cultures in Burk's sucrose (58.4 mM) plus $\mathrm{NH}_{4}^{+}$ $(18 \mathrm{mM})$ the mutant washed out in four and the wild-type in two cases.

\section{DISCUSSION}

The mutants examined here were obtained by MNNG mutagenesis which can induce multiple mutations and were therefore not necessarily isogenic with the parent strain MCD-1. However, they grew as rapidly as MCD-1 under most conditions tested and it is therefore unlikely that they possessed any new metabolic characters affecting growth behaviour other than the lack of hydrogenase activity. They had different secondary phenotypes and were presumed not to be siblings. Their frequency of reversion was less than $5 \times 10^{3}$, the limit of the 'scrying' technique (Yates \& Robson, 1985). For these reasons they were considered adequate for use in this study.

Hydrogenase benefits $A$. chroococcum under $\mathrm{N}_{2}$-fixing but not $\mathrm{NH}_{4}^{+}$-utilizing conditions, which suggests that this occurs through recycling $\mathrm{H}_{2}$ produced by nitrogenase. The benefit was only observed at high growth rates or with sparse populations, which implies that hydrogenase assists the organism either by protecting against inhibition of nitrogenase by $\mathrm{O}_{2}$ or by providing extra energy through ATP synthesis rather than by protecting nitrogenase against inhibition of $\mathrm{N}_{2}$ reduction by $\mathrm{H}_{2}$. These conditions mimic those which a cell encounters on transfer of batch culture: high $\mathrm{pO}_{2}$, separation from neighbours, conditions favouring rapid growth. We conclude 
that hydrogenase can be crucially important to the initiation of diazotrophic growth or the maintenance of steady-states under stress (carbon limitation) at high growth rates but otherwise has little effect on the steady-state efficiency of diazotrophy in $A$. chroococcum.

The ability of the parent $\mathrm{Hup}^{+}$strain to out-compete the Hup ${ }^{-}$mutants at high $D$ values and, alternatively, to be dominated by the mutants at low $D$ values may be because of the different 'coupling' efficiencies to ATP synthesis of $\mathrm{H}_{2}$ - and carbon-dependent respiration under different conditions. Laane et al. (1979) showed that, in Azotobacter vinelandii particles, $\mathrm{H}_{2}$ oxidation yielded higher $\mathrm{P} / \mathrm{O}$ ratios at low $\mathrm{O}_{2}$ and lower $\mathrm{P} / \mathrm{O}$ ratios at high $\mathrm{O}_{2}$ concentrations than did malate oxidation.

If our results can be extended to legume symbiosis then hydrogenase activity would benefit carbon-limited but not $\mathrm{O}_{2}$-limited bacteroids. The physiological status of bacteroids may change according to the plant's environmental regime of temperature, illumination, hydration, etc. Such a situation would explain the contradictory reports regarding the benefits of hydrogenase in symbiotic systems.

We thank Mrs Frances Campbell for technical assistance and Miss Beryl Scutt for typing the manuscript. O.M. A. wishes to thank the British Council for support.

\section{REFERENCES}

BAKER, K. (1968). Low cost continuous culture apparatus. Laboratory Practice 17, 817-824.

Dalton, H. \& Postgate, J. R. (1969). Growth and physiology of Azotobacter chroococcum in continuous culture. Journal of General Microbiology 56, 307319.

Dixon, R. O. D. (1972). Hydrogenase in legume root nodule bacteroids: occurrence and properties. Archiv für Mikrobiologie 85, 193-201

Evans, H. J., Purohit, K., Cantrell, M. A., Eisbrenner, G., Russell, S. A., Hanus, F. J. \& LEPO, J. E. (1981). Hydrogen losses and hydrogenases in nitrogen fixing systems. In Current Perspective in Nitrogen Fixation, pp. 84-96. Edited by A. H. Gibson \& W. E. Newton, Canberra: Australian Academy of Science.

Evans, H. J., Hanus, F. J., Russell, S. A., Harker, A. R., Lambert, G. R. \& Dalton, D. A. (1985). Biochemical characterisation, evaluation and genetics of $\mathrm{H}_{2}$ recycling in Rhizobium. In Nitrogen Fixation and $\mathrm{CO}_{2}$ Metabolism, pp. 3-11. Edited by P. W. Ludden \& J. E. Burris. New York: Elsevier.

Haugland, R. A., Hanus, F. J., Cantrell, M. A. \& Evans, H. J. (1983). Rapid colony screening method for identifying hydrogenase activity in Rhizobium japonicum. Applied and Environmental Microbiology 45, $892-897$.

LaAne, C., HaAker, H. \& Veeger, C. (1979). On the efficiency of oxidative phosphorylation in membrane vesicles of Azotobacter vinelandii and of Rhizobium leguminosarum bacteroids. European Journal of Biochemistry 97, 369377.

Newton, J. W., Wilson, P. W. \& Burris, R. H. (1953). Direct demonstration of ammonia as an intermediate in nitrogen fixation by Azotobacter. Journal of Biological Chemistry 204, 445-451.

Partridge, C. D. P. \& Yates, M. G. (1982). Effect of chelating agents on hydrogenase in Azotobacter chroococcum: evidence that nickel is required for hydrogenase synthesis. Biochemical Journal 204, 339-344.

Postgate, J. R. (1982). The Fundamentals of Nitrogen Fixation. Cambridge: Cambridge University Press.

Postgate, J. R., Partridge, C. D. P., Robson, R. L., Simpson, F. B. \& Yates, M. G. (1982). A method for screening for hydrogenase negative mutants of Azotobacter chroococcum. Journal of General Microbiology 128, 905-908.

Robson, R. L. \& Postgate, J. R. (1980). Oxygen and hydrogen in biological nitrogen fixation. Annual Review of Microbiology 34, 183-207.

Robson, R. L., Chesshyre, J. A., WheEler, K., Jones, R., Woodley, P. R. \& Postgate, J. R. (1984). Genome size and complexity in Azotobacter chroococcum. Journal of General Microbiology 130, 16031612.

Walker, C. C., Partridge, C. D. P. \& Yates, M. G. (1981). The effect of nutrient limitation on hydrogen production by nitrogenase in continuous cultures of Azotobacter chroococcum. Journal of General Microbiology 124, 317-327.

YATES, M. G. \& ROBSON, R. L. (1985). Mutants of Azotobacter chroococcum defective in hydrogenase activity. Journal of General Microbiology 131, 1459 1466.

Yates, M. G., Walker, C. C., Partridge, C. D. P., Pedrosa, F. O., Stephan, M. \& Dobereiner, J. (1981). $\mathrm{H}_{2}$ metabolism and nitrogenase activity in Azotobacter chroococcum and Azospirillum brasilense. In Current Perspectives in Nitrogen Fixation, pp. 97 100. Edited by A. H. Gibson \& W. E. Newton. Canberra: Australian Academy of Science. 